\title{
Bones, breasts, and bisphosphonates: rationale for the use of zoledronic acid in advanced and early breast cancer
}

This article was published in the following Dove Press journal:

Breast Cancer:Targets and Therapy

I4 March 201।

Number of times this article has been viewed

\section{Allan Lipton}

Milton S. Hershey Medical Center, Pennsylvania State University, Hershey, PA, USA
Correspondence: Allan Lipton

Department of Medicine, The Milton

S. Hershey Medical Center,

500 University Drive, Hershey,

PA, USA I 7033

Tel +I (7I7) 53I-5960

Fax +I (7I7) 53I-5076

Email alipton@hmc.psu.edu
Abstract: Bisphosphonates inhibit osteoclast-mediated bone resorption, thereby inhibiting the release of growth factors necessary to promote cancer cell growth, differentiation, and tumor formation in bone. These agents have demonstrated efficacy for delaying the onset and reducing the incidence of skeletal-related events in the advanced breast cancer setting, and have been shown to prevent cancer therapy-induced bone loss in the early breast cancer setting. Emerging clinical data indicate that the role of bisphosphonates in advanced and early breast cancer is evolving. Retrospective analyses and recent clinical trial data show that zoledronic acid may improve outcomes in some patients with breast cancer. Data from ABCSG-12 and ZO-FAST suggest that zoledronic acid may improve disease-free survival in the adjuvant breast cancer setting in postmenopausal women or women with endocrine therapy-induced menopause, and recent data from a predefined subset of the AZURE trial added to the anticancer story. However, the overall negative AZURE trial also raises questions about the role of bisphosphonates as an anticancer agent in patients with breast cancer. Overall, these data suggest that the addition of zoledronic acid to established anticancer regimens may have potential anticancer benefits in specific patient populations, although more studies are required to define its role.

Keywords: anticancer, adjuvant therapy, bone metastasis, skeletal, zoledronic acid

\section{The burden of bone metastases in women with advanced breast cancer}

The impact of breast cancer continues to be felt worldwide with more than 1 million new cases identified each year, ${ }^{1}$ and 254,650 new cases in 2009 in the United States alone. ${ }^{2}$ Although the primary tumor is often effectively treated with surgical resection and chemotherapy or endocrine therapy, cancer cells that escape the local site have a predilection for metastasis to bone, an environment that may help them survive during adjuvant therapy. As a result, distant metastases can develop in bone. Approximately $65 \%$ to $75 \%$ of women with advanced breast cancer will ultimately develop bone metastases, which can lead to skeletal-related events (SREs) such as pathologic fractures, spinal cord compression, hypercalcemia of malignancy, bone pain requiring palliative radiotherapy, and orthopedic surgery. ${ }^{3}$ Skeletal-related events can be severely debilitating, and may result in a significant reduction in functional independence and quality of life. Furthermore, SREs are associated with increased morbidity and mortality, and pathologic fractures have been associated with a significant increase in the risk of death in women with advanced breast cancer $(32 \% ; P<0.01){ }^{4}$ 


\section{Managing bone metastases with bisphosphonates}

Women with bone metastases from breast cancer often require palliative therapy (radiotherapy and analgesics) to prevent further bone destruction and to manage the pain associated with malignant bone disease. The presence of bone lesions frequently leads to an increase in the rate of osteoclast-mediated bone resorption. Bisphosphonates, antiresorptive agents that inhibit osteoclast function, have demonstrated efficacy for delaying the onset and reducing the incidence of SREs and controlling pain. ${ }^{5-8}$ During bone resorption, bisphosphonates bind to mineralized bone surfaces and are ingested by osteoclasts, wherein they block activation signals and can induce apoptosis.

Clodronate, ibandronate, pamidronate, and zoledronic acid (ZOL) are bisphosphonates that have demonstrated efficacy for delaying the onset and reducing the incidences of SREs and reducing the pain associated with bone metastases. ${ }^{9}$ These bisphosphonates have demonstrated varying activity in SRE-prevention trials in patients with multiple myeloma, metastatic breast cancer, prostate cancer, and lung cancer (Table 1). ${ }^{10-29}$ However, it should be noted that pamidronate and ZOL are the only bisphosphonates approved in the metastatic breast cancer setting in the United States. ${ }^{30,31}$ Recently, the antiresorptive agent denosumab also gained approval in the United States for the prevention of SREs in patients with bone metastases from solid tumors, including breast cancer. ${ }^{32}$ Current National Comprehensive Cancer
Network (NCCN) guidelines for breast cancer recommend initiation of antiresorptive therapy (ZOL, pamidronate, or denosumab) if there is plain radiographic evidence of bone destruction, and continuation of antiresorptive therapy until there is substantial decline in patient performance status. ${ }^{33}$ Antiresorptive therapy is not currently recommended for the prevention of bone metastases.

However, evidence suggests that the benefits of bisphosphonates may extend beyond the reduction of SREs in patients with breast cancer. Preclinical trials have demonstrated that this class of agent has anticancer effects. ${ }^{34}$ Anticancer activities include direct inhibition of cancer cell proliferation, induction of apoptosis, synergy with cytotoxic anticancer therapies, inhibition of angiogenesis, and activation of antitumor T-cell immunity. Moreover, modifying the bone microenvironment surrounding cancer cells may have powerful anticancer effects. ${ }^{35,36}$ Within the bone marrow, the release of bone matrix-derived growth factors by cancer cells during osteoclast-mediated bone resorption can promote cancer cell growth, differentiation, and tumor formation in bone. Inhibition of osteoclast-mediated bone resorption by bisphosphonates can prevent the release of these growth factors, thereby potentially preventing cancer recurrence.

Additional insights into the effects of the bisphosphonates ZOL and pamidronate on clinical outcomes have been reached through the retrospective analyses of biochemical markers of bone turnover. These markers may indicate the severity of metastatic bone disease. For example, elevated

Table I Summary of BP SRE prevention trials outcomes

\begin{tabular}{|c|c|c|c|c|c|c|}
\hline Author & $\mathbf{B P}$ & Dosage & Tumor type & $\mathbf{N}$ & SRE risk reduction & $P$ value \\
\hline Lahtinen $1992^{19}$ & $\mathrm{CLO}$ & $2400 \mathrm{mg} q$ day PO for $2 \mathrm{yr}$ & MM & 350 & Yes & $<0.00 I^{a}$ \\
\hline McCloskey 1998²1 & CLO & 1600 mg q day PO & MM & 536 & Yes & $\leq 0.06$ \\
\hline Brincker $1998^{14}$ & PAM & 300 mg q day PO & $M M$ & 300 & No & 0.27 \\
\hline Berenson $1998^{10}$ & PAM & $90 \mathrm{mg}$ IV q 4 wk for 2 I cycles & $M M$ & 392 & Yes & 0.015 \\
\hline Menssen $2002^{22}$ & IBN & $2 \mathrm{mg}$ IV q mo for $12-24 \mathrm{mo}$ & MM & 198 & No & NS \\
\hline Berenson 2001"I & ZOL; PAM & 2 or 4 mg IV q mo; 90 mg & $M M$ & 280 & Yes & $<0.05^{\mathrm{b}}$ \\
\hline Rosen $2001,2003^{24,25}$ & $\mathrm{ZOL}$ & 4 or $8 \mathrm{mg}$ IV q 3-4 wk & $\mathrm{MM} / \mathrm{BC}$ & 1648 & Yes & 0.025 \\
\hline Gimsing $2010^{16}$ & PAM & 30 or $90 \mathrm{mg}$ IV q mo for $3 \mathrm{yr}$ & MM & 504 & Yes & NS \\
\hline Kohno $2005^{17}$ & $\mathrm{ZOL}$ & $4 \mathrm{mg}$ IV q 4 wk for I yr & $\mathrm{BC}$ & 228 & $41 \%$ & 0.019 \\
\hline Aredia study 18 and $192000^{20}$ & PAM & 90 mg IV q 3-4 wk & $\mathrm{BC}$ & 751 & $23 \%$ & $<0.001^{c}$ \\
\hline Body $2003^{12}$ & IBN & 6 mg IV q 3-4 wk & $\mathrm{BC}$ & 312 & $18 \%$ & $0.04^{c}$ \\
\hline Body $2004^{13}$ & IBN & 50 mg q day PO & $\mathrm{BC}$ & 564 & $14 \%$ & $0.08^{c}$ \\
\hline Kristensen $1999^{18}$ & $\mathrm{CLO}$ & 1600 mg q day PO & $\mathrm{BC}$ & 100 & $31 \%$ & $0.03^{c}$ \\
\hline Paterson $1993^{23}$ & $\mathrm{CLO}$ & 1600 mg q day PO & $\mathrm{BC}$ & 173 & $17 \%$ & $0.03^{c}$ \\
\hline Tubiana-Hulin $200 \mathrm{I}^{29}$ & $\mathrm{CLO}$ & 1600 mg q day PO & $\mathrm{BC}$ & 144 & $8 \%$ & $0.03^{c}$ \\
\hline Dearnaley $2003^{15}$ & CLO & 2080 mg q day PO & PC & 311 & Yes & 0.02 \\
\hline Small $2003^{28}$ & PAM & 90 mg IV q 3 wk & PC & 378 & No & NS \\
\hline Saad $2002^{27}$ & ZOL & 4 or $8 \mathrm{mg}$ IV q $3-4$ wk & PC & 643 & $11 \%$ & 0.02 \\
\hline Rosen $2003^{26}$ & ZOL & 4 or $8 \mathrm{mg}$ IV q $3-4$ wk & LC & 773 & Yes & 0.017 \\
\hline
\end{tabular}

Notes: aSRE of pain only; 'SRE of radiation to bone only; 'Percentage decrease in SRE risk and $P$ value derived from the Cochrane database meta-analysis. ${ }^{9}$

Abbreviations: BC, breast cancer; BP, bisphosphonate; CLO, clodronate; IBN, ibandronate; IV, intravenous; LC, lung cancer; MM, multiple myeloma; mo, month; NS, not significant; PAM, pamidronate; PC, prostate cancer; PO, orally; q, every; SRE, skeletal-related event; ZOL, zoledronic acid. 
urinary N-telopeptide of type I collagen (NTX) levels are associated with increased risk of SREs, disease progression, and death. ${ }^{37,38}$ An exploratory analysis of patients with breast cancer, prostate cancer, myeloma, and non-small cell lung cancer found that approximately $30 \%$ of women with bone metastases from breast cancer have high NTX levels ( $\geq 100 \mathrm{nmol} / \mathrm{mmol}$ creatinine). ${ }^{38}$ Patients with high and moderate NTX levels had a 2-fold increase in their risk of skeletal complications and disease progression compared with patients with low NTX levels $(P<0.001$ for all). High NTX levels in each solid tumor category were associated with a 4- to 6-fold increased risk of death on study, and moderate NTX levels associated with a 2- to 4-fold increased risk compared with low NTX levels $(P<0.001$ for all). ${ }^{38}$ In a retrospective subset analysis of a phase III trial comparing ZOL with pamidronate in patients with breast cancer, ${ }^{39} 60 \%$ of patients had elevated baseline NTX levels. Most patients $(76 \%)$ treated with ZOL normalized their NTX levels after 3 months of therapy, and normalization of NTX significantly reduced the risk of SREs and improved survival (Figure 1). ${ }^{39}$

Similar effects of ZOL were observed in a retrospective analysis of 3 large, phase III trials $(\mathrm{N}=1341)$ in patients with breast cancer $(n=578)$, prostate cancer $(n=472)$, or non-small cell lung cancer and other solid tumors $(n=291)$ and elevated baseline NTX levels, which found that ZOL normalized or maintained normal NTX levels in most patients with bone metastases. ${ }^{40}$ Indeed, normalization of NTX levels within 3 months of treatment was associated with reduced risks of skeletal complications and death compared with persistently elevated NTX. ${ }^{40}$

In addition to studies in breast cancer, ZOL has also demonstrated survival benefits in several prospective studies in other tumor types. Notably, ZOL has shown improved survival in small pilot studies with patients with metastatic bladder cancer ${ }^{41}$ or multiple myeloma, ${ }^{42}$ and in a large phase III clinical trial in patients with multiple myeloma $(\mathrm{N}=1960) .{ }^{43}$ Together, these data support the potential

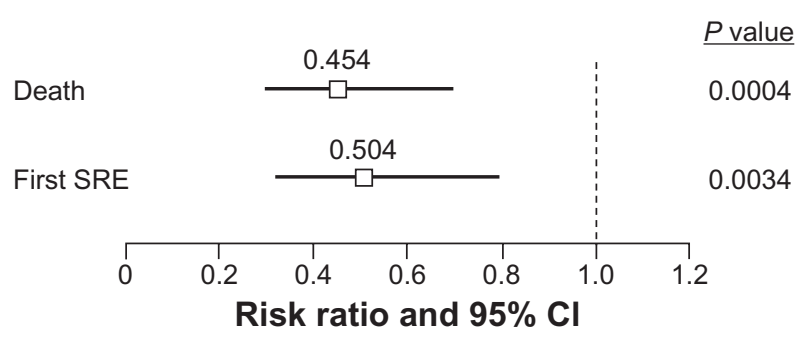

Figure I Kaplan-Meier estimates of survival by baseline and 3-month $\mathrm{N}$-telopeptide of type I collagen (NTX) levels in women with bone metastases from BC.

Reprinted with permission from Lipton et al. Oncologist. 2007; 12(9): 1035-1043. ${ }^{39}$

Abbreviations: $\mathrm{Cl}$, confidence interval; SRE, skeletal-related event. survival benefits of ZOL in patients with bone metastases from advanced cancer.

\section{Adjuvant zoledronic acid therapy in early breast cancer}

Current techniques for screening and early diagnosis of breast cancer and refinement of first-line and adjuvant treatments for breast cancer have led to increased survival in this setting. However, chemotherapy often causes ovarian failure and early menopause, which leads to osteoporosis. ${ }^{44}$ The use of hormone replacement therapy is successful in preventing bone loss after natural and surgical menopause, but it cannot be utilized in breast cancer survivors because of its potential effect on dormant tumor cells. ${ }^{45}$ Moreover, estrogen-depleting regimens are common adjuvant therapies for early breast cancer, and have been associated with significantly increased risk of fractures. ${ }^{6,46,47}$ The use of antiresorptive therapy is beneficial in this setting for preventing bone loss, and ZOL has consistently protected against bone loss associated with ovarian ablative and adjuvant hormonal therapies for early breast cancer. Furthermore, ZOL therapy may have effects beyond bone health in patients with early breast cancer. ${ }^{48,49}$

In preclinical models, ZOL has been shown to block breast cancer metastasis to bone,${ }^{50}$ thereby preventing the vicious cycle of bone resorption and tumor formation. Data from translational clinical trials suggest that ZOL may affect the viability of cancer cells via its effects on bone metabolism. ${ }^{51-54}$ Indeed, ZOL may modify the bone microenvironment surrounding cancer cells through indirect effects on the ability of disseminated tumor cells (DTCs) to survive and/or reactivate to initiate tumor recurrence. ${ }^{36}$ This concept has been supported by studies of the effects of ZOL on DTCs. The detection of DTCs in the bone marrow of women with early stage breast cancer is prognostic of early relapse. ${ }^{55,56}$ DTCs can lie dormant in bone marrow for extended periods of time before becoming active and metastasizing to secondary sites. ${ }^{36}$

In pilot clinical trials in patients with breast cancer, ZOL reduced DTC persistency (Table 2). ${ }^{51,53,54,57}$ In one study, 120 patients with newly diagnosed breast cancer received neoadjuvant chemotherapy with or without ZOL (4 mg every 3 weeks) for 1 year. Of the women who were DTC-positive at baseline, $70 \%$ of ZOL-treated patients became DTC-negative by 3 months, versus $53 \%$ in the chemotherapy-alone group $(P=0.054) .{ }^{51}$ Furthermore, $87 \%$ of ZOL-treated patients who were DTC-negative at baseline remained DTC-negative at 3 months compared with $60 \%$ of patients receiving chemotherapy alone $(P=0.03) .{ }^{51}$ Patients who were DTC-positive after completing adjuvant 
Table 2 Effect of ZOL on DTC levels in patients with early breast cancer

\begin{tabular}{|c|c|c|c|}
\hline Study & $\mathbf{N}$ & $\begin{array}{l}\text { Adjuvant chemo/endocrine } \\
\text { therapy } \pm \text { ZOL dose }\end{array}$ & Results \\
\hline Aft $2010^{51}$ & 120 & $4 \mathrm{mg} q 3 \mathrm{wk} \mathrm{IV} \times \mathrm{I} \mathrm{yr}$ & $\begin{array}{l}\text { Among patients with DTC } C^{+} \text {BM at baseline, ZOL } \downarrow \text { percentage of } \\
\text { patients with persistent DTC at } 3 \text { mo }(P=0.054) \text { vs no ZOL }\end{array}$ \\
\hline $\operatorname{Lin} 2008^{57}$ & 45 & $4 \mathrm{mg} \mathrm{q} \mathrm{mo} \mathrm{IV} \times 2 \mathrm{yr}$ & $\begin{array}{l}\text { ZOL } \downarrow \text { DTC number in BM at } 12 \mathrm{mo}(P=0.0006, \mathrm{n}=36) \text { and } 24 \mathrm{mo} \\
(P=0.0026, \mathrm{n}=24) \text { vs baseline }\end{array}$ \\
\hline Rack $2010^{53}$ & 172 & $4 \mathrm{mg} \mathrm{q} \mathrm{mo} \mathrm{IV} \times 6 \mathrm{mo}$ & $\begin{array}{l}\mathrm{ZOL} \downarrow \text { percentage of patients who remained } \mathrm{DTC}^{+} \text {at } 6 \mathrm{mo} \\
(P=0.099) \text { vs no } \mathrm{ZOL}\end{array}$ \\
\hline Solomayer $2008^{54}$ & 76 & $4 \mathrm{mg} q \mathrm{mo} \mathrm{IV} \times 24 \mathrm{mo}$ & $\begin{array}{l}\text { Among patients with } \mathrm{DTC}^{+} \mathrm{BM} \text { at baseline, } \mathrm{ZOL} \downarrow \text { percentage } \\
\text { of patients with persistent DTC at } 12 \mathrm{mo}(P=0.009) \text { vs no ZOL }\end{array}$ \\
\hline
\end{tabular}

Abbreviations: BC, breast cancer; BM, bone metastases; DTC, disseminated tumor cells; IV, intravenous; mo, month; q, every; wk, week; yr, year; ZOL, zoledronic acid; ', positive.

chemotherapy for breast cancer $(\mathrm{N}=45)$ who received monthly ZOL for 2 years experienced a significant reduction in the prevalence of DTCs at 12 and 24 months compared with baseline $(P \leq 0.001){ }^{52,57}$ In each of these 3 studies, ZOL was generally well tolerated. ${ }^{51-54,57}$ The ability of ZOL to reduce DTCs in patients with breast cancer may result from anticancer synergy between endocrine therapy and ZOL, which has been demonstrated in preclinical studies. ${ }^{58}$

Data from 3 phase III clinical trials suggest that ZOL may have anticancer benefits in the adjuvant breast cancer setting (Figure 2). ${ }^{48,59,60}$ In the ABCSG-12 trial, premenopausal women with early stage, endocrine-responsive breast cancer $(\mathrm{N}=1803)$ received goserelin and tamoxifen $\pm \mathrm{ZOL}$ or goserelin and anastrozole \pm ZOL for 3 years. Analyses after a median follow-up of 48 months showed that the addition of ZOL to adjuvant endocrine therapy reduced the risk of disease progression by $36 \%$ compared with endocrine therapy alone. ${ }^{48}$ Overall, ZOL improved disease-free survival (DFS) by $32 \%$ (hazard ratio $[\mathrm{HR}]=0.68 ; 95 \%$ confidence interval $[\mathrm{CI}]=0.51,0.91 ; P=0.009)$, decreased the risk of disease progression $36 \%(P=0.01),{ }^{48}$ and produced a trend toward

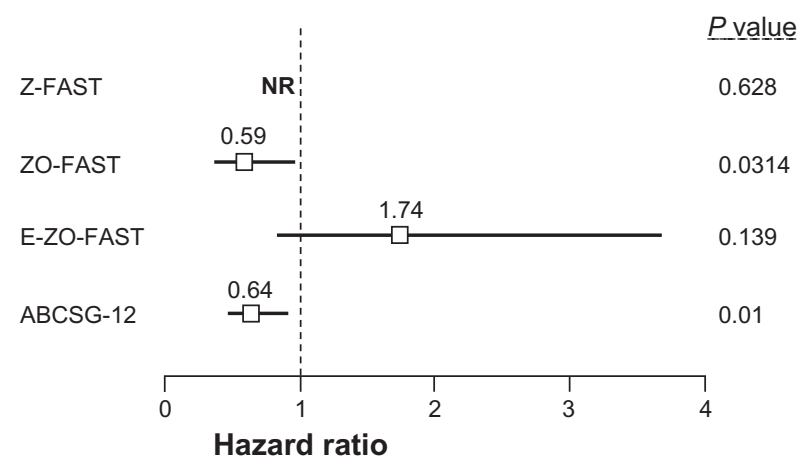

Figure 2 Forest plot of DFS outcomes in adjuvant ZOL BC trials. The ZO-FAST, E-ZO-FAST, and ABCSG- 12 phase III clinical trials in patients with early BC showed that ZOL improved DFS.

Data from Gnant et al, ${ }^{48}$ Eidtmann et al, ${ }^{59}$ and Llombart et al. ${ }^{60}$

Abbreviations: BC, breast cancer; DFS, disease-free survival; NR, not reported; ZOL, zoledronic acid. improved overall survival (OS) versus no ZOL $(\mathrm{HR}=0.66$ $[0.41,1.09] ; P=0.1) .^{49}$ Furthermore, at 48 and 62 months' follow-up, the DFS benefits of ZOL remained significant compared with hormonal therapy alone, suggesting a longterm carryover benefit from the initial 3 years of $\mathrm{ZOL}$ treatment. ${ }^{49}$

In 3 companion studies, Z-FAST $(\mathrm{N}=602)$, ZO-FAST $(\mathrm{N}=1065)$, and E-ZO-FAST $(\mathrm{N}=527)$, postmenopausal women with early breast cancer receiving letrozole were randomized to receive upfront or delayed ZOL (4 mg via 15-minute infusion every 6 months) for 5 years. ${ }^{60,61}$ Although disease recurrence was a secondary endpoint in all 3 trials, DFS was an exploratory endpoint that none of the trials were powered to detect. ${ }^{59,60,62}$ Despite this, the largest of the 3 trials (ZO-FAST, $\mathrm{N}=1065$ ) showed improved DFS in patients who received upfront ZOL. After a median follow-up of 36 months, the upfront-ZOL group had a significant $41 \%$ reduction in the risk of having a DFS event compared with the delayed-ZOL group (HR $=0.588$ [0.361-0.959]; $\log$-rank $P=0.0314),{ }^{59}$ and these benefits were maintained through 60 months' follow-up (HR $=0.66$ [0.44-0.97]; $\log$-rank $P=0.0375) .{ }^{63}$ Furthermore, an integrated 24-month analysis of the Z-FAST and ZO-FAST trials showed a $42.7 \%$ improvement in DFS in patients receiving upfront $\mathrm{ZOL}$ compared with delayed ZOL $(\mathrm{HR}=0.573$ [0.358-0.916] $\log$-rank $P=0.0183) .{ }^{61}$ However, there was no significant difference in DFS between the upfront- and delayed-ZOL groups in the Z-FAST $(\mathrm{N}=602)$ and E-ZO-FAST $(\mathrm{N}=527)$ studies. ${ }^{64}$

The AZURE trial is assessing the anticancer activity of ZOL in patients with early breast cancer. Patients with highrisk, early stage breast cancer $(\mathrm{N}=3360)$ received anticancer therapy alone or standard therapy plus a tapered dosing schedule of ZOL (4 mg every 3-4 weeks $\times 6$; 4 mg every 3 months $\times 8 ; 4 \mathrm{mg}$ every 6 months $\times 5) \cdot{ }^{65}$ In the neoadjuvant substudy $(\mathrm{n}=205)$ of the AZURE trial, ZOL plus neoadjuvant 
anticancer therapy significantly reduced residual invasive tumor size compared with anticancer therapy alone (43\%; $P=0.006) .{ }^{66}$ Furthermore, patients who received ZOL had a 2-fold improvement in their pathologic complete response rates. ${ }^{66}$ This small substudy suggests that the synergy between ZOL and chemotherapy can have a direct anticancer effect on the primary tumor.

Unlike the other adjuvant breast cancer trials described, the AZURE study was not limited to hormone-responsive breast cancer. The patient population included both premenopausal and postmenopausal women, and standard anticancer therapy included adjuvant chemotherapy as well as endocrine therapy. Overall, the trial results were negative; the adjuvant use of ZOL did not improve the primary endpoint of DFS in the overall patient population $(\mathrm{HR}=0.98$; $P=0.79$ ) at a median follow-up of 59 months, although there was a nonsignificant trend toward improved OS for $\mathrm{ZOL}$ versus control $(\mathrm{HR}=0.85 ; P=0.07) .{ }^{65}$ Interestingly, prospective protocol-defined subgroup analyses based on menopausal status showed that ZOL significantly improved DFS $(\mathrm{HR}=0.76 ; P<0.05)$ in patients who were at least 5 years postmenopausal at baseline $(\mathrm{n}=1041)$ and $\mathrm{OS}(\mathrm{HR}=0.71 ; P=0.017)$ when women of unknown postmenopausal status but age $>60$ years at baseline $(n=1101)$ were included in the subset analysis. ${ }^{65}$ Zoledronic acid also reduced each type of recurrence both in and outside bone (HR and $P$ value were not reported) versus control in the postmenopausal subset $(\mathrm{n}=1101) .{ }^{65}$ These results may seem inconsistent with data showing significant DFS benefits from ZOL in premenopausal women in ABCSG-12. However, the premenopausal populations in these 2 studies were markedly different. In ABCSG-12, premenopausal women underwent complete ovarian suppression with goserelin therapy plus either tamoxifen or anastrozole, which resulted in endocrine-therapy induced menopause, while most premenopausal women in the AZURE study received chemotherapy rather than endocrine therapy. The data from these large, prospective clinical trials suggest that ZOL may have anticancer activity in some patient populations, although further studies are needed to clarify which patients may receive the greatest benefit from therapy.

\section{Discussion}

Bone health in women with breast cancer is an important concern throughout the disease course. Endocrine therapy for women with early breast cancer combined with ZOL to protect bone health may also have the advantage of reducing the incidence of metastases. In women whose disease has already spread to bone, antiresorptive therapies have established utility for delaying the onset and reducing the incidence of potentially debilitating SREs. Bisphosphonates in general and ZOL specifically have been shown to block multiple steps in the process of tumor metastasis either alone or in combination with anticancer agents.

Clinical treatment guidelines that address bone health in women with breast cancer have been developed ${ }^{33}$ and are continually evolving as new clinical trial data become available. In addition to being a clearly established therapy for the prevention of SREs in patients with bone metastases from breast cancer, ZOL has been shown to reduce disease recurrence, improve DFS and, with longer follow-up, may also improve OS in pre- and postmenopausal women with early endocrine-responsive breast cancer. Data in this setting are promising but still investigational, as trial outcomes have varied for different patient populations.

Furthermore, guidelines for the prevention of SREs in patients with bone metastases support the use of ZOL, pamidronate, or denosumab in patients with breast cancer; ZOL or denosumab in patients with any solid tumor; and ZOL in patients with multiple myeloma. In the advanced cancer setting, prognostic indicators (eg, bone markers) of ZOL activity may ultimately allow for personalization of interventions, potentially providing a greater benefit-risk profile; however, further data are needed. Recent trials also suggest that adding ZOL to adjuvant endocrine therapy in some patient populations may protect bone health and improves clinical outcomes beyond adjuvant therapy alone. However, although ABCSG-12, the Z-/ZO-/E-ZO-FAST companion trials, and the postmenopausal subset analysis in the AZURE study have shown improved outcomes with the addition of ZOL in the adjuvant breast cancer setting, the overall results of the AZURE study were negative. The role of ZOL therapy in the adjuvant setting is evolving and ongoing studies of antiresorptive therapies (ie, ZOL and denosumab) will define this role.

\section{Acknowledgments}

Financial support for medical editorial assistance was provided by Novartis Pharmaceuticals. I thank Duprane Pedaci Young, PhD, ProEd Communications, Inc. ${ }^{\circledR}$, for her medical editorial assistance with this manuscript.

\section{Disclosure}

Dr Lipton has served as a consultant for Amgen and Novartis; has received honoraria from Amgen, Novartis, and Genentech; has received research funding from Novartis, 
Monogram Biosciences, and Oncogene Sciences; and has given expert testimony for Novartis.

\section{References}

1. Garcia M, Jemal A, Ward EM, et al. Global Cancer Facts and Figures 2007. Atlanta, GA: American Cancer Society; 2007.

2. American Cancer Society. Cancer Facts and Figures 2010. Atlanta, GA: American Cancer Society; 2010.

3. Coleman RE. Skeletal complications of malignancy. Cancer. 1997; 80(8 Suppl):1588-1594.

4. Saad F, Lipton A, Cook R, Chen YM, Smith M, Coleman R. Pathologic fractures correlate with reduced survival in patients with malignant bone disease. Cancer. 2007;110(8):1860-1867.

5. Clezardin P, Fournier P, Boissier S, Peyruchaud O. In vitro and in vivo antitumor effects of bisphosphonates. Curr Med Chem. 2003;10(2): 173-180.

6. Gnant M, Mlineritsch B, Luschin-Ebengreuth G, et al. Adjuvant endocrine therapy plus zoledronic acid in premenopausal women with early-stage breast cancer: 5-year follow-up of the ABCSG-12 bonemineral density substudy. Lancet Oncol. 2008;9(9):840-849.

7. $\mathrm{Ha} \mathrm{TC}, \mathrm{Li} \mathrm{H}$. Meta-analysis of clodronate and breast cancer survival. Br J Cancer. 2007;96(12):1796-1801.

8. Hershman DL, McMahon DJ, Crew KD, et al. Zoledronic acid prevents bone loss in premenopausal women undergoing adjuvant chemotherapy for early-stage breast cancer. J Clin Oncol. 2008;26(29): 4739-4745.

9. Pavlakis N, Schmidt R, Stockler M. Bisphosphonates for breast cancer. Cochrane Database Syst Rev. 2005(3):CD003474.

10. Berenson JR, Lichtenstein A, Porter L, et al. Long-term pamidronate treatment of advanced multiple myeloma patients reduces skeletal events. Myeloma Aredia Study Group. J Clin Oncol. 1998;16(2): 593-602.

11. Berenson JR, Rosen LS, Howell A, et al. Zoledronic acid reduces skeletal-related events in patients with osteolytic metastases. Cancer. 2001;91(7):1191-1200.

12. Body JJ, Diel IJ, Lichinitser MR, et al. Intravenous ibandronate reduces the incidence of skeletal complications in patients with breast cancer and bone metastases. Ann Oncol. 2003;14(9):1399-1405.

13. Body JJ, Diel IJ, Lichinitzer M, et al. Oral ibandronate reduces the risk of skeletal complications in breast cancer patients with metastatic bone disease: results from two randomised, placebo-controlled phase III studies. Br J Cancer. 2004;90(6):1133-1137.

14. Brincker H, Westin J, Abildgaard N, et al. Failure of oral pamidronate to reduce skeletal morbidity in multiple myeloma: a double-blind placebo-controlled trial. Danish-Swedish co-operative study group. Br J Haematol. 1998;101(2):280-286.

15. Dearnaley DP, Sydes MR, Mason MD, et al. A double-blind, placebocontrolled, randomized trial of oral sodium clodronate for metastatic prostate cancer (MRC PR05 Trial). J Natl Cancer Inst. 2003;95(17): $1300-1311$

16. Gimsing P, Carlson K, Turesson I, et al. Effect of pamidronate $30 \mathrm{mg}$ versus $90 \mathrm{mg}$ on physical function in patients with newly diagnosed multiple myeloma (Nordic Myeloma Study Group): a double-blind, randomised controlled trial. Lancet Oncol. 2010;11(10): 973-982.

17. Kohno N, Aogi K, Minami H, et al. Zoledronic acid significantly reduces skeletal complications compared with placebo in Japanese women with bone metastases from breast cancer: a randomized, placebo-controlled trial. J Clin Oncol. 2005;23(15):3314-3321.

18. Kristensen B, Ejlertsen B, Groenvold M, Hein S, Loft H, Mouridsen HT. Oral clodronate in breast cancer patients with bone metastases: a randomized study. J Intern Med. 1999;246(1):67-74.

19. Lahtinen R, Laakso M, Palva I, Virkkunen P, Elomaa I. Randomised, placebo-controlled multicentre trial of clodronate in multiple myeloma. Finnish Leukaemia Group. Lancet. 1992;340(8827): 1049-1052.
20. Lipton A, Theriault RL, Hortobagyi GN, et al. Pamidronate prevents skeletal complications and is effective palliative treatment in women with breast carcinoma and osteolytic bone metastases: long term follow-up of two randomized, placebo-controlled trials. Cancer. 2000; 88(5):1082-1090.

21. McCloskey EV, MacLennan IC, Drayson MT, Chapman C, Dunn J, Kanis JA. A randomized trial of the effect of clodronate on skeletal morbidity in multiple myeloma. MRC Working Party on Leukaemia in Adults. Br J Haematol. 1998;100(2):317-325.

22. Menssen HD, Sakalova A, Fontana A, et al. Effects of long-term intravenous ibandronate therapy on skeletal-related events, survival, and bone resorption markers in patients with advanced multiple myeloma. J Clin Oncol. 2002;20(9):2353-2359.

23. Paterson AH, Powles TJ, Kanis JA, McCloskey E, Hanson J, Ashley S. Double-blind controlled trial of oral clodronate in patients with bone metastases from breast cancer. J Clin Oncol. 1993;11(1):59-65.

24. Rosen LS, Gordon D, Kaminski M, et al. Zoledronic acid versus pamidronate in the treatment of skeletal metastases in patients with breast cancer or osteolytic lesions of multiple myeloma: a phase III, double-blind, comparative trial. Cancer J. 2001;7(5):377-387.

25. Rosen LS, Gordon D, Kaminski M, et al. Long-term efficacy and safety of zoledronic acid compared with pamidronate disodium in the treatment of skeletal complications in patients with advanced multiple myeloma or breast carcinoma: a randomized, double-blind, multicenter, comparative trial. Cancer. 2003;98(8):1735-1744.

26. Rosen LS, Gordon D, Tchekmedyian S, et al. Zoledronic acid versus placebo in the treatment of skeletal metastases in patients with lung cancer and other solid tumors: a phase III, double-blind, randomized trial - the Zoledronic Acid Lung Cancer and Other Solid Tumors Study Group. J Clin Oncol. 2003;21(16):3150-3157.

27. Saad F, Gleason DM, Murray R, et al. A randomized, placebo-controlled trial of zoledronic acid in patients with hormone-refractory metastatic prostate carcinoma. J Natl Cancer Inst. 2002;94(19):1458-1468.

28. Small EJ, Smith MR, Seaman JJ, Petrone S, Kowalski MO. Combined analysis of two multicenter, randomized, placebo-controlled studies of pamidronate disodium for the palliation of bone pain in men with metastatic prostate cancer. J Clin Oncol. 2003;21(23):4277-4284.

29. Tubiana-Hulin M, Beuzeboc P, Mauriac L, et al. Double-blinded controlled study comparing clodronate versus placebo in patients with breast cancer bone metastases. Bull Cancer. 2001;88(7):701-707.

30. Zometa [prescribing information]. East Hanover, NJ: Novartis Pharmaceuticals Corporation; 2009.

31. Aredia [prescribing information]. East Hanover, NJ: Novartis Pharmaceuticals Corporation; 2008.

32. Xgeva [prescribing information]. Thousand Oaks, CA: Amgen Inc.; 2010 .

33. National Comprehensive Cancer Network. NCCN Clinical Practice Guidelines in Oncology. Breast Cancer V.2.2011. www.ncen.org. Published 2010. Updated December 6, 2010. Accessed January 5, 2011.

34. Clezardin P. Anti-tumour activity of zoledronic acid. Cancer Treat Rev. 2005;31(Suppl 3):1-8.

35. Gnant M. Bisphosphonates in the prevention of disease recurrence: current results and ongoing trials. Curr Cancer Drug Targets. 2009;9(7): 824-833.

36. Meads MB, Hazlehurst LA, Dalton WS. The bone marrow microenvironment as a tumor sanctuary and contributor to drug resistance. Clin Cancer Res. 2008;14(9):2519-2526.

37. Brown JE, Cook RJ, Major P, et al. Bone turnover markers as predictors of skeletal complications in prostate cancer, lung cancer, and other solid tumors. J Natl Cancer Inst. 2005;97(1):59-69.

38. Coleman RE, Major P, Lipton A, et al. Predictive value of bone resorption and formation markers in cancer patients with bone metastases receiving the bisphosphonate zoledronic acid. J Clin Oncol. 2005;23(22):4925-4935.

39. Lipton A, Cook RJ, Major P, Smith MR, Coleman RE. Zoledronic acid and survival in breast cancer patients with bone metastases and elevated markers of osteoclast activity. Oncologist. 2007;12(9): $1035-1043$. 
40. Lipton A, Cook R, Saad F, et al. Normalization of bone markers is associated with improved survival in patients with bone metastases from solid tumors and elevated bone resorption receiving zoledronic acid. Cancer. 2008;113(1):193-201.

41. Zaghloul MS, Boutrus R, El-Hossieny H, KaderYA, El-Attar I, Nazmy M. A prospective, randomized, placebo-controlled trial of zoledronic acid in bony metastatic bladder cancer. Int J Clin Oncol. 2010; 15(4):382-389.

42. Aviles A, Nambo MJ, Neri N, Castaneda C, Cleto S, Huerta-Guzman J. Antitumor effect of zoledronic acid in previously untreated patients with multiple myeloma. Med Oncol. 2007;24(2):227-230.

43. Morgan GJ, Davies FE, Gregory WM, et al; National Cancer Research Institute Haematological Oncology Clinical Study Group. First-line treatment with zoledronic acid as compared with clodronic acid in multiple myeloma (MRC Myeloma IX): a randomised controlled trial. Lancet. 2010;376(9757):1989-1999.

44. Padmanabhan N, Wang DY, Moore JW, Rubens RD. Ovarian function and adjuvant chemotherapy for early breast cancer. Eur J Cancer Clin Oncol. 1987;23(6):745-748

45. Pfeilschifter J, Diel IJ. Osteoporosis due to cancer treatment: pathogenesis and management. J Clin Oncol. 2000;18(7):1570-1593.

46. Gnant MF, Mlineritsch B, Luschin-Ebengreuth G, et al. Zoledronic acid prevents cancer treatment-induced bone loss in premenopausal women receiving adjuvant endocrine therapy for hormone-responsive breast cancer: a report from the Austrian Breast and Colorectal Cancer Study Group. J Clin Oncol. 2007;25(7):820-828.

47. Eastell R, Adams JE, Coleman RE, et al. Effect of anastrozole on bone mineral density: 5-year results from the anastrozole, tamoxifen, alone or in combination trial 18233230. J Clin Oncol. 2008;26(7):1051-1057.

48. Gnant M, Mlineritsch B, Schippinger W, et al. Endocrine therapy plus zoledronic acid in premenopausal breast cancer. $N$ Engl J Med. 2009; 360(7):679-691.

49. Gnant M, Mlineritsch B, Stoeger H, et al. Mature results from ABCSG-12: Adjuvant ovarian suppression combined with tamoxifen or anastrozole, alone or in combination with zoledronic acid, in premenopausal women with endocrine-responsive early breast cancer. Presented at 46th Annual Meeting of the American Society of Clinical Oncology (ASCO); June 4-8, 2010; Chicago, IL. Abstract 533.

50. Ottewell PD, Deux B, Monkkonen H, et al. Differential effect of doxorubicin and zoledronic acid on intraosseous versus extraosseous breast tumor growth in vivo. Clin Cancer Res. 2008;14(14):4658-4666.

51. Aft R, Naughton M, Trinkaus K, et al. Effect of zoledronic acid on disseminated tumour cells in women with locally advanced breast cancer: an open label, randomised, phase 2 trial. Lancet Oncol. 2010; 11(5):421-428.

52. Greenberg S, Park JW, Melisko ME, et al. Effect of adjuvant zoledronic acid (ZOL) on disseminated tumor cells (DTC) in the bone marrow (BM) of women with early-stage breast cancer (ESBC): updated results. Presented at 46th Annual Meeting of the American Society of Clinical Oncology; June 4-8, 2010; Chicago, IL. Abstract 1002.

53. Rack B, Juckstock J, Genss EM, et al. Effect of zoledronate on persisting isolated tumour cells in patients with early breast cancer. Anticancer Res. 2010;30(5):1807-1813.

54. Solomayer EF, Gebauer G, Hirnle P, et al. Influence of zoledronic acid on disseminated tumor cells (DTC) in primary breast cancer patients. Presented at 31st Annual San Antonio Breast Cancer Symposium; December 10-14, 2008; San Antonio, TX. Abstract 2048.
55. Janni W, Rack B, Schindlbeck C, et al. The persistence of isolated tumor cells in bone marrow from patients with breast carcinoma predicts an increased risk for recurrence. Cancer. 2005;103(5):884-891.

56. Schindlbeck C, Kampik T, Janni W, et al. Prognostic relevance of disseminated tumor cells in the bone marrow and biological factors of 265 primary breast carcinomas. Breast Cancer Res. 2005;7(6): R1174-R1185.

57. Lin AY, Park JW, Scott J, et al. Zoledronic acid as adjuvant therapy for women with early stage breast cancer and disseminated tumor cells in bone marrow. J Clin Oncol. 2008;26(Suppl):20s. Abstract 559.

58. Neville-Webbe HL, Coleman RE, Holen I. Combined effects of the bisphosphonate, zoledronic acid and the aromatase inhibitor letrozole on breast cancer cells in vitro: evidence of synergistic interaction. $\mathrm{BrJ}$ Cancer. 2010;102(6):1010-1017.

59. Eidtmann H, de Boer R, Bundred N, et al. Efficacy of zoledronic acid in postmenopausal women with early breast cancer receiving adjuvant letrozole: 36-month results of the ZO-FAST Study. Ann Oncol. 2010; 21(11):2188-2194.

60. Llombart A, Frassoldati A, Paija O, et al. Zoledronic acid prevents aromatase inhibitor-associated bone loss in postmenopausal women with early breast cancer receiving adjuvant letrozole: E-ZO-FAST 36-month follow-up. Presented at 2009 ASCO Breast Cancer Symposium; October 8-10, 2009; San Francisco, CA. Abstract 213.

61. Frassoldati A, Brufsky A, Bundred N, et al. Effect of zoledronic acid in postmenopausal women with early breast cancer receiving adjuvant letrozole: a 24-month integrated follow-up of the Z-FAST/ZO-FAST trials. Presented at 11 th St. Gallen Breast Cancer Conference; March 11-14, 2009; St. Gallen, Switzerland. Abstract 132.

62. Brufsky AM, Bosserman LD, Caradonna RR, et al. Zoledronic acid effectively prevents aromatase inhibitor-associated bone loss in postmenopausal women with early breast cancer receiving adjuvant letrozole: Z-FAST study 36-month follow-up results. Clin Breast Cancer. 2009;9(2):77-85.

63. de Boer R, Bundred N, Eidtmann H, et al. The effect of zoledronic acid on aromatase inhibitor-associated bone loss in postmenopausal women with early breast cancer receiving adjuvant letrozole: the ZO-FAST study 5-year final follow-up. Presented at 33rd Annual San Antonio Breast Cancer Symposium; December 8-12, 2010; San Antonio, TX Poster P5-11-01.

64. Coleman R, Bundred N, de Boer R, et al. Impact of zoledronic acid in postmenopausal women with early breast cancer receiving adjuvant letrozole: Z-FAST, ZO-FAST, and E-ZO-FAST. Presented at 32nd Annual San Antonio Breast Cancer Symposium; December 9-13, 2009; San Antonio, TX. Abstract 4082.

65. Coleman RE, Thorpe HC, Cameron D, et al. Adjuvant treatment with zoledronic acid in stage II/III breast cancer. The AZURE trial (BIG 01/04). Presented at 33rd Annual San Antonio Breast Cancer Symposium; December 8-12, 2010; San Antonio, TX. Abstract S4-S5.

66. Coleman RE, Winter MC, Cameron D, et al. The effects of adding zoledronic acid to neoadjuvant chemotherapy on tumour response: exploratory evidence for direct anti-tumour activity in breast cancer. Br J Cancer. 2010;102:1099-1105.
Breast Cancer: Targets and Therapy

\section{Publish your work in this journal}

Breast Cancer: Targets and Therapy is an international, peerreviewed open access journal focusing on breast cancer research, identification of therapeutic targets and the optimal use of preventative and integrated treatment interventions to achieve improved outcomes, enhanced survival and quality of life for the cancer patient.

\section{Dovepress}

View the full aims and scopes of this journal here. The manuscript management system is completely online and includes a very quick and fair peer-review system, which is all easy to use. Visit http:// www.dovepress.com/testimonials.php to read real quotes from published authors. 